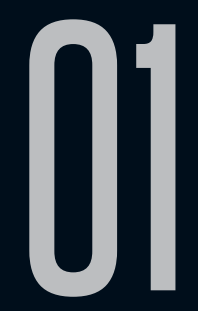

\title{
ENTREVISTA COM NATÁLIA BORGES POLESSO
}

Marcio Markendorf

Nadege Ferreira Rodrigues Jardim

Marcio Markendorf é Professor Associado do Departamento de Artes da Universidade Federal de Santa Catarina (UFSC), com atuação no Curso de Cinema e na Pós-graduação em Literatura.

Nadege Ferreira Rodrigues Jardim, cujo nome artístico é Diedra Roiz, escritora e mestranda do Programa de Pós-Graduação em Literatura da UFSC, com bolsa do CNPQ. Possui graduação em Artes Cênicas pela UNIRIO - Universidade Federal do Estado do Rio de Janeiro (UNIRIO, 1999) e graduação em Direito pela UERJ - Universidade do Estado do Rio de Janeiro (UERJ, 1994). Tem experiência na área de Literatura, com ênfase em literatura com protagonismo lésbico e literatura LGBT e na área de Artes, com ênfase em Adaptação de texto e Direção Teatral. 


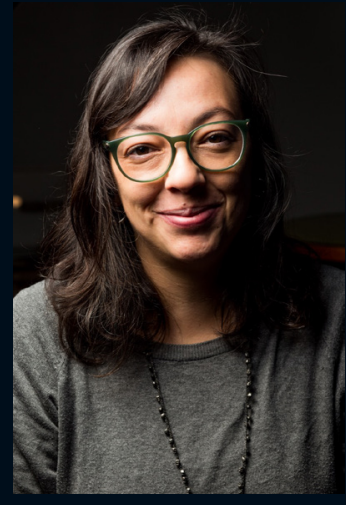

Natália Borges Polesso é escritora, professora, tradutora e pesquisadora de pós-doutorado com bolsa CAPES na Universidade de Caxias do Sul. Doutora em Teoria da Literatura pelo Programa de Pós-Graduação em Letras da Pontifícia Universidade Católica (PUC-RS), com período de doutoradosanduíche na Sorbonne Université, mestre em Letras pelo Programa de Pós-Graduação em Letras, Cultura e Regionalidade na Universidade de Caxias do Sul, é autora de diversos livros, dentre eles: Recortes para álbum de fotografia sem gente (2013) - vencedor do prêmio Açorianos de Literatura em 2013 - e Amora (2015) - vencedor dos prêmios AGES - livro do ano (2016), Açorianos de Literatura (2016) e 10 lugar no Prêmio Jabuti nas categorias Contos e Escolha do Leitor. Recentemente, publicou Controle (2019) - vencedor do prêmio Minuano de Literatura 2020 na Categoria Ficção - romance/novela e Corpos Secos (2020). Em 2017, foi selecionada para a coletânea Bogotá39, que reúne os 39 escritores mais promissores da América Latina com menos de 40 anos.

P.: Como muitas figuras do folclore brasileiro, o corpo seco está associado a uma maldição, algo resultante de um mau comportamento, o que obviamente tem uma intenção educativa moralizante. Como surgiu a ideia de revitalizar essa lenda a partir da mitologia zumbi?

R.: Antes de tudo, quero dizer que fui convidada para este projeto pela Luisa Geisler, que já tinha conversado superficialmente com o Marcelo Ferroni (que é editor dela na Alfaguara) sobre escrever um livro apocalíptico. A Luisa me contou e eu achei a ideia bacana, achei que isso seria um desafio, e disse que ela poderia contar comigo sim, caso o projeto andasse. E andou. 
De modo que a primeira ideia que chegou a mim, quando recebi o convite, foi a de escrevermos uma narrativa longa, coletivamente, e que envolvesse um apocalipse zumbi. Mas conforme fomos conversando, decidimos não usar a palavra zumbi, nem pensar nos termos de sua mitologia original caribenha, mas pensar mais nos seus cognatos fílmicos. Uma das coisas que aventamos também era que fosse uma história brasileira e possível no Brasil, não um pastiche (não tenho nada contra pastiches como recurso estético, mas não era o caso). Pensamos a história em linhas gerais e fomos decidindo sobre as nossas personagens e como se relacionariam ou como se encontrariam. A partir desse vírus, o Baculovirus anticarsia, e do desenvolvimento de um fungo, o qual fizemos nossas personagens chamarem de doença do Corpo Seco ou Corposecagem, fomos desenvolvendo os acontecimentos da história em termos mais amplos. O Corpo Seco original é isso mesmo que vocês definiram na pergunta, e sim, é do folclore brasileiro, e era isso que queríamos: fazer uma história brasileira, com conceitos que vincularíamos a essa ideia, para a qual utilizamos a definição de Câmara Cascudo. Essa escolha, devemos ao Samir Machado de Machado, que trouxe o termo ao grupo e que foi imediatamente aceito. Nós o deturpamos um pouco (o termo, não o Samir, risos) na nossa ficção coletiva, para servir aos propósitos da nossa trama. Originalmente, Corpo-seco é uma pessoa tão horrível, tão má, que agredia até a mãe em vida e que ao morrer, nem deus nem o diabo o quiseram, aliás, nem a terra o quis e assim o regurgitou, por assim dizer. Assim, esse cadáver, 
esse morto-vivo, não podendo descansar, fica vagando e assombrando as pessoas vivas. Nós achamos que pensar nessa ideia era uma boa saída para os nossos corpos-secos. Queria também comentar que nossa editora, Luara França, teve um papel fundamental nesta aventura. Nem sempre se enaltece devidamente o trabalho de um editor ou de uma editora, neste caso, é preciso reforçar que quem montou o quebra-cabeça, que nós autores inventamos, foi a Luara.

\section{P.: A literatura brasileira não tem tradição no gênero horror} e o folclore brasileiro não parece interessar muito os/as escritores/as. Você atribui alguma causa a essa questão?

R.: É engraçado isso. De fato, podemos pensar que não temos uma tradição no gênero horror, mas veja, nossa epígrafe é de Erico Verissimo, um dos mais importantes escritores brasileiros, do livro Incidente em Antares (1971), e Incidente em Antares talvez seja um dos primeiros livros sobre mortos-vivos, ambientado no Brasil. Não se pode dizer que é uma tradição, mas também não se pode negar sua existência histórica já de algum tempo. Eu acredito que hoje, já temos bastantes autores que escrevem horror, e temos um exemplo de best-seller, o Raphael Montes, mas temos também Bruno Ribeiro, que inclusive ganhou recentemente o Prêmio Machado, um prêmio para literatura de terror e suspense. Aliás, o trabalho da editora DarkSide, uma casa especializada neste tipo de literatura, e mesmo iniciativas em pequenas editoras ou de autores e autoras independentes, vêm se destacando cada vez mais no cenário da literatura contemporânea. Esses dias li um livro chamado Onde as velas incendeiam (2020), de Naiara Medeiros, que saiu pela Patuá. 
Não sabia do que se tratava, descobri durante a leitura, a qual comecei para ler algo leve durante a pandemia (hahahha), que se tratava de um livro de contos de horror. Então, embora, não tenhamos tradição neste gênero, isso não significa que não temos produção dele presentemente, de modo que discordo da ideia de que esse não é um assunto que interessa escritores e escritoras, eu acredito que interessa sim.

P.: O romance multiautoral Corpos Secos acaba dialogando com outras obras com temática de epidemia, como Eu sou a lenda, de Richard Matheson, talvez a mais evidente. Há outras referências de narrativas de contágio e contaminação que serviram de inspiração e podem ser citadas?

R.: Se não me engano, todes nós lemos Eu sou a lenda, como referência, e para além disso, lemos outros livros, e dividimos nossas perspectivas dessas leituras. Eu li World war Z, de Max Brooks, mas confesso que li en passant, assistimos a muitos filmes e séries (os que vieram dessas duas obras citadas, por certo), tais como The reZort, Zombiland, Madrugada dos mortos, Santa Clarita's Diet, além de conversarmos sobre alguns jogos de videogame que abordam de algum modo o tema, como Fallout. Quando nos encontrávamos para conversar (virtualmente, pois foi assim que escrevemos) trocávamos breves ideias sobre o que havíamos assistido, especialmente sobre o modo como a "doença" era transmitida, como se espalhava, quanto tempo demoraria para que o caos fosse instaurado, para que as instituições caíssem, para que a comunicação cessasse. Tudo isso foi discutido a partir de narrativas pré-existentes e assim estabelecemos os parâmetros da nossa. 
P.: Como boa parte das narrativas da mitologia zumbi, Corpos Secos efetua uma crítica social. No livro responsabilizase o governo pela epidemia, em razão da liberação de agrotóxicos. Poderia comentar mais sobre essa pauta?

R.: Primeiramente, nossa ideia era criar uma narrativa sobre um apocalipse de mortos-vivos. Dar enfoque à má gerência de uma crise sanitária por parte do governo, à má gerência da epidemia também, é claro, além da liberação dos agrotóxicos foi algo que "aconteceu", porque precisávamos pensar no contexto e nas consequências do nosso evento principal. Segundamente, precisávamos de um gatilho e, como vocês disseram, esses livros trazem sempre, de algum modo, críticas sociais. O caso dos agrotóxicos no Brasil é pornográfico, é absurdo, é a morte. Isso é um dos nossos grandes problemas sociais, que inclusive estão sempre causando outros efeitos colaterais, além de impasses em acordos econômicos. O que vai ressoar num dos nossos principais problemas como país: a reforma agrária e distribuição de renda (já que essa é uma pauta também importante na perspectiva econômica). Fora que estamos comendo veneno. E como eu particularmente tenho pensado essas ideias de colapso e de natureza/sociedade, quando sugeri, achamos que seria um bom gatilho.

P.: Há estudos sobre o uso de glifosato na lavoura que apontam para crescimento da incidência de autismo. Você acredita que agrotóxicos e alimentos transgênicos possam, no futuro, gerar doenças em larga escala? 
R.: Eu não sei responder essa pergunta, eu sou ficcionista! Há muitas controvérsias sobre a ligação entre o glifosfato e o Transtorno do Espectro Autista (TEA) e eu prefiro não fazer essa associação, nem tenho base para comentar esse aspecto. Sem contar que TEA não é exatamente uma doença, mas uma condição neurológica bastante ampla e variável entre seus indivíduos. Agora se a pergunta diz respeito a eu acreditar que comer veneno, que ingerir pesticidas e respirar pesticidas pode nos deixar doentes de câncer, de problemas gástricos, respiratórios, sanguíneos, alergênicos etc., a resposta é: com certeza, eu acredito que sim. E não no futuro. Creio que agora já estamos vendo e sentindo as consequências dessa indústria. A mim, particularmente, interessa usar esses índices para escrever, tenho pensado narrativas assim. Meu próximo livro é sobre o colapso e tem muito a ver com o tema.

\section{P.: A falta de governo central e as hordas de corpos Secos} funcionam como uma alegoria do Brasil atual?

R.: Autores nunca são as pessoas mais indicadas para essas análises. Acho que isso é mais trabalho dos críticos (risos). Posso falar de onde partimos e que recursos usamos para criar a narrativa que serviria aos nossos propósitos. Logicamente pode-se fazer uma ligação, mas há que se lembrar que começamos a escrever este livro em 2018 e não tínhamos a noção real de que seria tão parecido (risos nervosos). Não havia nem sinal de uma pandemia, apesar de que muitos estudos nesse campo têm despontado a possibilidade de vivermos grandes pandemias já faz algum tempo. O que posso dizer é que mudamos todo o nosso plano de divulgação 
e marketing do livro, que seria meio Orson Wells, pensando em A guerra dos mundos. Havíamos pensado em cartazes como se fossem do "ministério da saúde" e anúncios sobre prevenção e cuidados, mas nada disso foi levado adiante, pois a realidade nos atropelou. O Samir disse em alguma entrevista que não era necessário nenhum grande exercício de futurologia para prever como um governo federal de negacionistas ineptos faria a gestão de uma crise (sanitária ou não). Enfim, as coisas são mais complexas, agora, para a continuação estamos pensando em nuances que englobem também o que estamos passando, porém, a pandemia de covid-19 nunca existiu no mundo de Corpos Secos, então lidaremos com outras demandas.

P.: Considerando o histórico preconceito biopolítico contra gays - acentuado com a epidemia de HIV/AIDS nos anos 1980 -, é em tom provocativo que Corpos Secos torne a única pessoa com anticorpos capazes de produzir uma vacina um homem cis homossexual?

R.: Corpos Secos tem a ideia de dissidência de gênero em seu cerne. Isso não foi exatamente combinado. Ficamos livres para escolher como e com quem queríamos narrar as histórias. As personagens são homens gays, mulheres lésbicas, drag queens, velhes, crianças, mulheres arrancadas do padrão etc., no mais, a parte do Mateus é do Samir Machado de Machado, que tem por princípio criar personagens gays. Acho que essas escolhas têm mais a ver com nossos projetos literários individuais, como no meu caso, que sempre priorizo a escrita de mulheres lésbicas e bissexuais, não heteronormativas. 
P.: Corpos Secos explora o fato, comum a ficções de holocausto zumbi, de que maior que a ameaça dos mortos-vivos são os vivos lutando pela sobrevivência. Você concorda com essa fantasia pessimista sobre os seres humanos em meio a uma crise?

R.: Não usaria a palavra holocausto aí, nem como catástrofe, nem como genocídio, nem vincularia a um extermínio étnico. Sobre concordar com uma "fantasia pessimista" sobre seres humanos lidando com uma crise, olhando ao redor, aqui neste 2021, não chamaria de fantasia. E também não diria que é pessimismo. Diria que é uma realidade muito dura que se destacou durante a pandemia, mas que afeta a maior parte das pessoas todos os dias. Evidentemente que os efeitos da colonialidade e do capitalismo na nossa estrutura social, econômica e cultural são peças-chave para entendermos como chegamos aqui, mas a pandemia realmente destacou nossas desigualdades. Basta lembrar que os bilionários do mundo ficaram mais ricos neste ínterim. Isso é muito triste e muito revoltante.

P.: Dona Carmem descobre uma forma natural de afastar as criaturas, o que nos remete à construção de saberes da medicina popular, não tradicional e farmacêutica. Do seu ponto de vista, essa personagem reforça ou desconstrói o estereótipo hippie construído pelo capitalismo?

R.: Dona Carmem é uma personagem construída um tanto para trazer um alívio cômico para a história. Ela tem essa sabedoria popular, associada a uma teimosia, não diria que ela é hippie, ao menos não a pensei dessa forma. Pensei mais como uma 
pessoa do interior, que me é sempre uma questão cara. Minhas personagens, em geral, são de cidades pequenas ou do interior. Não sei como ela é lida. Já recebi comentários de que é negacionista. Eu não acho que seja o caso, não a construí com esse intuito. Ali se veria mais uma questão de etarismo e da ideia que velhes não são vistos como pessoas autônomas, que têm o direito de decidir sobre as coisas. Dona Carmen está lidando bem com a catástrofe, está se cuidando ao seu modo, e se recusa a seguir com os filhos, Conrado e Constância. Isso não quer dizer que seja negacionista, quer dizer que fez uma escolha. E o foco está também no respeito a essa decisão. Ela é comentada, Constância e Conrado não concordam, mas não a obrigam a ir com eles. Contudo, é claro que com o prisma da pandemia, as coisas se tornam mais complexas. Temos visto velhes deprimides, que optam por ver os seus entes querides, porque não querem esperar uma vacina, porque acham que podem morrer sozinhes, não de covid, mas de depressão ou de qualquer outra doença, parecem dizer que não têm o tempo que nós temos. E, de certo modo, é verdade. É uma questão muito complexa.

P.: Apesar do COVID-19 ter sido considerado no início da pandemia como um "vírus democrático", que não faz distinção entre as pessoas, sabemos que seu impacto está longe de ser igualitário. Você considera o Baculovirus anticarsia, que causa a Síndrome de Matheson-França em Corpos Secos, mais ou menos democrático?

R.: Um vírus é um vírus e ponto. A questão reside nas pessoas, mais precisamente na resposta social, como vocês bem colocaram. 
Acho que respondi um pouco dessa pergunta na resposta de número 8.

P.: Como foi lançar um livro sobre epidemias em meio a atual pandemia do novo coronavírus?

R.: Estranho. Mas lançamos em abril/maio. Nem tínhamos noção real de como seria. Foi interessante também porque nos lançou imediatamente na questão das lives e eventos virtuais, meio sem saber como isso aconteceria. Uma coisa que tenho pensado é que, sim, é legal que tudo fique gravado e acessível, mas também penso que gostava de quando os eventos e esses encontros eram efêmeros. 